\title{
Rickettsiosis transmitidas por garrapatas en las Américas: avances clínicos y epidemiológicos, y retos en el diagnóstico
}

\author{
Marylin Hidalgo', Álvaro A. Faccini-Martínez¹, Gustavo Valbuena² \\ 1 Grupo de Enfermedades Infecciosas, Departamento de Microbiología, Facultad de Ciencias, Pontificia \\ Universidad Javeriana, Bogotá, D.C., Colombia
}

2 Pathology Department, University of Texas Medical Branch, Texas, USA

Las rickettsiosis son entidades clínicas de tipo zoonótico, causadas por bacterias intracelulares estrictas de los géneros Rickettsia y Orientia, pertenecientes a la familia Rickettsiaceae. Su ecología está determinada por factores ambientales y la presencia de vectores específicos que condicionan el establecimiento y la epidemiología en diferentes regiones del mundo.

En las Américas, durante el siglo XX, únicamente eran reconocidas tres de estas enfermedades: la fiebre manchada de las Montañas Rocosas, el tifus epidémico y el tifus endémico, Sin embargo, a partir del año 2000 se han descrito mas de 10 especies diferentes previamente desconocidas en este continente, tanto en artrópodos como en casos clínicos, hecho que permite clasificarlas como entidades clínicas emergentes y reemergentes.

Dadas las manifestaciones clínicas de las enfermedades causadas por rickettsias, siendo la gran mayoría inespecíficas y, por lo mismo, compartidas con otras enfermedades infecciosas, especialmente virales y bacterianas, han sido enmarcadas entre los diagnósticos diferenciales del síndrome febril agudo, tanto en áreas urbanas como tropicales. En la actualidad, se cuenta con métodos diagnósticos directos e indirectos, que son útiles en la identificación del agente infeccioso, en este caso, causante de rickettsiosis.

Palabras clave: Rickettsia, Américas, infecciones por Rickettsia, epidemiología, diagnóstico, zoonosis.

doi: http://dx.doi.org/10.7705/biomedica.v33i0.1466

\section{Tick-borne rickettsioses in the Americas: clinical and epidemiological advances, and diagnostic challenges}

Rickettsioses are a group of zoonotic diseases caused by strict intracellular bacteria of the genus Rickettsia and Orientia which belong to the Rickettsiaceae family. Their ecology is influenced by environmental factors and the presence of specific vectors that determine the establishment and epidemiology in different world regions. In America, during the $20^{\text {th }}$ century, only three of these diseases were recognized: Rocky Mountain spotted fever, epidemic typhus and endemic typhus. However, since 2000, more than 10 different species that had previously been unknown in this continent have been described, both in arthropods and in clinical cases, fact that classifies them as emerging and reemerging diseases. Given the clinical manifestations of the diseases caused by rickettsias, being the majority unspecific and, therefore, shared with other infectious diseases, especially viral and bacterial, they have been framed within the differential diagnoses of acute febrile syndrome in urban and tropical areas. Nowadays, there are direct and indirect diagnostic methods, which are useful in the definition of the infectious agent, in this case, the cause of rickettsioses.

Key words: Rickettsia, Americas, Rickettsia infections, epidemiology, diagnosis, zoonoses. doi: http://dx.doi.org/10.7705/biomedica.v33i0.1466

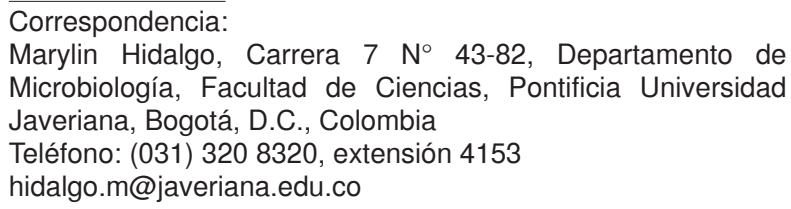

Recibido: 20/11/12; aceptado:02/03/13
Las rickettsiosis son entidades clínicas de tipo zoonótico, causadas por bacterias estrictas de los géneros Rickettsia y Orientia, pertenecientes a la familia Rickettsiaceae (1). En la actualidad, con base en análisis filogenéticos, se proponen dos clasificaciones para las diferentes especies de este

Contribución de los autores:

Álvaro Adolfo Faccini se encargó de la revisión de la literatura científica y la redacción del manuscrito.

Marylin Hidalgo y Gustavo Valbuena asesoraron la revisión, sugirieron modificaciones de estilo y corrigieron el manuscrito. 
género. En la primera se describen cuatro grupos: grupo de las fiebres manchadas ( $R$. rickettsii, $R$. conorii y $R$. parkeri, entre otras), grupo del tifus ( $R$. prowazekii y $R$. typhi), grupo transicional $(R$. akari, $R$. australis y $R$. felis) y grupo ancestral ( $R$. bellii y $R$. canadensis) (2). En la segunda, se contemplan únicamente dos grupos con subgrupos: grupo de las fiebres manchadas (subgrupo $R$. rickettsii, subgrupo $R$. massiliae, subgrupo $R$. helvetica y subgrupo $R$. akari) y grupo del tifus (subgrupo $R$. prowazekii) (3) (cuadro 1).

En condiciones naturales, las rickettsias patógenas suelen utilizar artrópodos y pequeños mamíferos como reservorios y huéspedes amplificadores, siendo el ser humano un huésped accidental (35). El hombre se ve afectado después de la inoculación bacteriana mediante la picadura de garrapatas (gran parte de las especies del grupo de las fiebres manchadas) o ácaros ( $R$. akari y Orientia tsutsugamushi) y por el contacto de abrasiones cutáneas con heces de pulgas ( $R$. typhi y $R$. felis) o piojos ( $R$. prowazekii) (36). Por lo anterior, hacen parte de las enfermedades transmitidas por vectores de importancia médica (37).

En cuanto a la fisiopatología, las células endoteliales son el blanco donde invaden y proliferan estos microorganismos, a excepción de R. akari (tropismo por los macrófagos), causando daño endotelial directo asociado a liberación de citocinas proinflamatorias y estrés por oxidación, lo que lleva a un proceso de vasculitis de pequeños y medianos vasos, acompañado de extravasación de líquidos $(2,38)$.

El cuadro clínico se caracteriza por fiebre de inicio agudo, síntomas inespecíficos, como malestar general, cefalea, mialgias, artralgias, y en algunas ocasiones, manifestaciones de tipo exantemático en piel. En los casos más graves, dado el daño vascular, suele producirse afectación pulmonar (edema, neumonía intersticial, síndrome de dificultad respiratoria del adulto), cerebral (meningoencefalitis, convulsiones, déficit neurológico), falla renal aguda y choque hipovolémico (39). Cabe resaltar que algunas de estas enfermedades presentan, entre sus manifestaciones clínicas dermatológicas, la escara de inoculación (única o múltiple), que se define como una lesión costrosa-necrótica con halo eritematoso circundante que determina el sitio de ingreso de las rickettsias (40).

En la actualidad, se reconocen, aproximadamente, 25 especies pertenecientes al género Rickettsia
(41), las cuales presentan una distribución mundial. Su ecología está determinada por factores ambientales y la presencia de vectores específicos que condicionan el establecimiento y las características epidemiológicas de determinadas rickettsiosis en diferentes regiones del mundo (1). En las Américas, durante el siglo XX, únicamente se reconocían tres de estas enfermedades: la fiebre manchada de las Montañas Rocosas, el tifus epidémico y el tifus endémico. Sin embargo, a partir del año 2000 se han descrito más de 10 especies diferentes previamente desconocidas en este continente, tanto en artrópodos como en casos clínicos, hecho que permite clasificarlas como entidades clínicas emergentes y reemergentes $(5,42)$. No obstante, en algunos países continúan siendo subdiagnosticadas debido a una pobre sospecha clínica, al hecho de ser confundidas con otras causas de síndrome febril agudo y, a pesar de que existen métodos diagnósticos estandarizados, muchos de ellos no están disponibles para las entidades médicas, presentan situaciones de reacción cruzada entre las diferentes especies del género Rickettsia o requieren instalaciones de alto nivel de complejidad $(5,43)$.

A continuación, se presenta una visión actual de las rickettsiosis transmitidas por garrapatas en las Américas y su papel como reto diagnóstico.

\section{Rickettsiosis transmitidas por garrapatas}

Las garrapatas hacen parte de los artrópodos vectores de mayor importancia en la transmisión de microorganismos al hombre y a los animales (37). Pertenecen al orden Parasitiformes, suborden Ixodida, y se subdividen en tres familias: Ixodidae, también llamadas "garrapatas de cuerpo duro" (mayor número de especies), Argasidae (garrapatas de cuerpo blando) y Nuttalliellidae (una sola especie, que no está presente en América y sin papel patógeno para el humano) (44). Por su parte, diferentes géneros de la familia Ixodidae están implicados en el papel vectorial y como reservorios o amplificadores de las rickettsias del grupo de las fiebres manchadas (45), los cuales requieren un periodo aproximado entre 6 y 24 horas de hematofagia continua en el ser humano, para la transmisión de estos microorganismos (46). En las Américas, las garrapatas de los géneros Dermacentor, Rhipicephalus y Amblyomma están fuertemente relacionadas con la transmisión de $R$. rickettsii, $R$. parkeri, $R$. massiliae y $R$. africae, siendo estas, las especies mas representativas en este continente $(5,47)$. 
Cuadro 1. Clasificaciones propuestas para las diferentes especies del género Rickettsia: en la parte superior, con base en Mansueto, et al., (2) y Renvoisé, et al., (4) y en la parte inferior, con base en Merhej, et al. (3); en negrilla, las especies relacionadas con garrapatas descritas en las Américas.

Clasificaciones propuestas para las diferentes especies del género Rickettsia

\begin{tabular}{|c|c|c|c|}
\hline Grupo & Especies & Países o regiones de las Américas & Enfermedad \\
\hline \multirow[t]{28}{*}{$\begin{array}{l}\text { Grupo de las fiebres } \\
\text { manchadas }\end{array}$} & R. rickettsii $(5,6)$ & $\begin{array}{l}\text { Canadá, Estados Unidos, México, } \\
\text { Costa Rica, Panamá, Colombia, Brasil } \\
\text { y Argentina }\end{array}$ & $\begin{array}{l}\text { Fiebre manchada de las } \\
\text { Montañas Rocosas }\end{array}$ \\
\hline & R. helvetica & & Fiebre aneruptiva \\
\hline & R. asiatica & & $\begin{array}{l}\text { Capacidad patógena } \\
\text { desconocida }\end{array}$ \\
\hline & R. tamurae & & $\begin{array}{l}\text { Sugestiva de fiebre } \\
\text { manchada }\end{array}$ \\
\hline & R. massiliae (7-9) & Estados Unidos y Argentina & Fiebre manchada \\
\hline & $\begin{array}{l}\text { Rickettsia sp. relacionada } \\
\text { con } \boldsymbol{R} \text {. aeschlimannii (10) }\end{array}$ & Bolivia & $\begin{array}{l}\text { Capacidad patógena } \\
\text { desconocida }\end{array}$ \\
\hline & R. montanensis $(11,12)$ & Canadá y Estados Unidos & $\begin{array}{l}\text { Capacidad patógena } \\
\text { desconocida }\end{array}$ \\
\hline & R. rhipicephali $(5,13)$ & Estados Unidos y Brasil & $\begin{array}{l}\text { Capacidad patógena } \\
\text { desconocida }\end{array}$ \\
\hline & $\begin{array}{l}\text { R. sibirica } \\
\text { subsp. sibirica }\end{array}$ & & $\begin{array}{l}\text { Tifus siberiano } \\
\text { transmitido por } \\
\text { garrapatas }\end{array}$ \\
\hline & $\begin{array}{l}\text { R. sibirica } \\
\text { subsp. mongolitimonae }\end{array}$ & & $\begin{array}{l}\text { Linfangitis asociada a } \\
\text { rickettsiosis }\end{array}$ \\
\hline & R. slovaca & & $\begin{array}{l}\text { DEBONEL-TIBOLA- } \\
\text { SENLAT }\end{array}$ \\
\hline & R. africae (14-17) & Islas del Caribe & $\begin{array}{l}\text { Fiebre africana } \\
\text { transmitida por } \\
\text { garrapatas }\end{array}$ \\
\hline & R. conorii subsp. conorii & & $\begin{array}{l}\text { Fiebre manchada del } \\
\text { Mediterráneo }\end{array}$ \\
\hline & R. conorii subsp. israelensis & & Fiebre manchada israelí \\
\hline & R. conorii subsp. caspia & & Fiebre de Astracán \\
\hline & R. conorii subsp. indica & & $\begin{array}{l}\text { Tifus indio transmitido } \\
\text { por garrapatas }\end{array}$ \\
\hline & R. heilongjiangensis & & $\begin{array}{l}\text { Rickettsiosis transmitida } \\
\text { por garrapatas del } \\
\text { lejano oriente }\end{array}$ \\
\hline & R. japonica & & $\begin{array}{l}\text { Fiebre manchada japonesa } \\
\text { u oriental }\end{array}$ \\
\hline & R. parkeri $(5,6)$ & $\begin{array}{l}\text { Estados Unidos, Brasil, Bolivia, Argentina } \\
\text { y Uruguay }\end{array}$ & Fiebre manchada \\
\hline & R. peacockii $(5,11)$ & Canadá y Estados Unidos & $\begin{array}{l}\text { Capacidad patógena } \\
\text { desconocida }\end{array}$ \\
\hline & R. honei & & $\begin{array}{l}\text { Fiebre manchada de las } \\
\text { islas Flinders }\end{array}$ \\
\hline & R. raoultii & & $\begin{array}{l}\text { DEBONEL-TIBOLA- } \\
\text { SENLAT }\end{array}$ \\
\hline & R. amblyommii $(6,18)$ & $\begin{array}{l}\text { Estados Unidos, Costa Rica, Panamá, } \\
\text { Guyana Francesa, Brasil y Argentina }\end{array}$ & $\begin{array}{l}\text { Capacidad patógena } \\
\text { desconocida }\end{array}$ \\
\hline & R. monacensis & & Fiebre manchada \\
\hline & R. marmionii & & $\begin{array}{l}\text { Fiebre manchada } \\
\text { australiana }\end{array}$ \\
\hline & Candidatus R. kellyi & & Fiebre manchada \\
\hline & $\begin{array}{l}\text { Candidatus } R . \text { andeanae } \\
(19-22)\end{array}$ & Estados Unidos, Perú, Chile y Argentina & $\begin{array}{l}\text { Capacidad patógena } \\
\text { desconocida }\end{array}$ \\
\hline & R. monteiroi (23) & Brasil & $\begin{array}{l}\text { Capacidad patógena } \\
\text { desconocida }\end{array}$ \\
\hline
\end{tabular}




\begin{tabular}{|c|c|c|}
\hline & $\begin{array}{l}\text { Rickettsia sp. cepa } \\
\text { Pampulha (24) }\end{array}$ & Brasil \\
\hline & $\begin{array}{l}\text { Rickettsia parkeri cepa } \\
\text { Atlantic rainforest }(25)\end{array}$ & Brasil \\
\hline & $\begin{array}{l}\text { Rickettsia sp. cepa NOD, } \\
\text { parkeri-like (26) }\end{array}$ & Brasil \\
\hline & $\begin{array}{l}\text { Rickettsia parkeri } \\
\text { cepa Bahia (27) }\end{array}$ & Brasil \\
\hline & $\begin{array}{l}\text { Rickettsia sp. cepa } \\
\text { colombianensi (28) }\end{array}$ & Colombia \\
\hline & $\begin{array}{l}\text { Rickettsia sp. cepa } \\
\text { 364D (29) }\end{array}$ & Estados Unidos \\
\hline & $\begin{array}{l}\text { Rickettsia filotipos G021 } \\
\text { y G022 (30) }\end{array}$ & Estados Unidos \\
\hline Grupo del tifus & R. prowazekii & \\
\hline & R. typhi & \\
\hline Grupo transicional & R. akari & \\
\hline & R. australis & \\
\hline & R. felis & \\
\hline Grupo ancestral & R. bellii $(6,31,32)$ & Estados Unidos, Perú, Brasil y Argentina \\
\hline & R. canadensis $(33,34)$ & Canadá y Estados Unidos \\
\hline
\end{tabular}

Género Orientia

O. tsutsugamushi
Capacidad patógena desconocida

Rickettsiosis asociada a escara de inoculación

Capacidad patógena desconocida

Rickettsiosis asociada a escara de inoculación

Capacidad patógena desconocida

Rickettsiosis asociada a escara de inoculación

Capacidad patógena desconocida

Tifus epidémico

Tifus endémico

Rickettsiosis pustulosa

Tifus de Queensland

transmitido por garrapatas

Fiebre manchada transmitida por pulgas Capacidad patógena desconocida

Capacidad patógena desconocida

Tifus de los matorrales
Grupo de las fiebres manchadas

\section{Subgrupo}

R. rickettsii

R. massiliae

R. helvetica

R. akari

\section{Especies}

R. rickettsii sp.

Rickettsia fiebre

de Astrakhan

cepa A-167

R. conorii cepa Malish 7

R. africae ESF-5

R. parkeri cepa Maculatum 20

$R$. sibirica subsp. mongolitimonae

R. slovaca N A 13 B

R. honei

$R$. japonica

R. heilongjiangensis

R. hulinensis

R. peacockii

Candidatus $R$. barbariae

Rickettsia endosimbionte de

Dermacentor hunteri

R. massiliae

Rickettsia sp. Bar 29

R. rhipicephali

R. aeschlimanii

$R$. montanensis

R. raoultii

Candidatus $R$. kulagi

Rickettsia sp. Dns

R. helvetica C9P9

$R$. asiatica

R. tamurae

R. monacensis

Rickettsia sp. IRS

R. akari cepa Hartford 


$\begin{array}{lll} & & \text { R. australis Philip } 1950 \\ \text { Grupo del tifus } & \text { R. prowazekii } & \begin{array}{l}\text { R. felis URWXCal2 } \\ \text { R. prowazekii cepa Madrid E } \\ \text { R. typhi cepa Wilmington }\end{array} \\ & \text { Grupo R. canadensis } & \begin{array}{l}\text { R. canadensis } \\ \text { Grupo R. bellii }\end{array} \\ \text { Género Orientia } & \text { O. bellii }\end{array}$

DEBONEL: DErmacentor BOrne Necrosis Erythema Lymphadenopathy; TIBOLA: TIck-Borne LymphAdenitis; SENLAT: Scalp Eschars and Neck LymphAdenopathy following Tick bites.

\section{Infección por Rickettsia rickettsii (fiebre manchada de las Montañas Rocosas)}

La fiebre manchada de las Montañas Rocosas es causada por $R$. rickettsii, perteneciente al grupo de las fiebres manchadas. Es la especie más patógena del género, con tasas de letalidad documentadas entre 23 y $85 \%$ en la era preantibiótica y del $5 \%$ con un tratamiento antibiótico adecuado $(48,49)$.

Clínicamente, presenta un periodo de incubación entre 2 y 14 días después de la picadura de la garrapata (aproximadamente, el $40 \%$ de los pacientes lo recuerda), con una media de 7 días (50). En las fases iniciales predominan los síntomas inespecíficos, como fiebre de inicio abrupto, malestar general, escalofríos, cefalea intensa, mialgias, artralgias, anorexia, vómito y dolor abdominal, entre otros, los cuales suelen simular infecciones virales (51). La tríada clínica clásica es fiebre, cefalea y exantema, presente únicamente en 3 a $5 \%$ en los primeros tres días, porcentaje que aumenta hasta 60 a $70 \%$ entre el día siete y el diez de la enfermedad (52). El exantema se inicia típicamente en las muñecas y los tobillos, como lesiones maculares eritematosas pequeñas no pruriginosas, para diseminarse de forma centrípeta, y alcanzar las extremidades (incluyendo palmas y plantas) y el tronco. En esta fase el exantema suele ser máculopapular asociado a petequias (53); sin embargo, el $10 \%$ de los pacientes nunca desarrollan manifestaciones exantemáticas; esto suele ser más frecuente en adultos mayores y afrodescendientes (54). En los casos graves pueden existir zonas de necrosis y gangrena en extremidades, sin ser frecuentes las hemorragias o la coagulación intravascular diseminada. Las complicaciones incluyen meningitis o meningoencefalitis, edema pulmonar, síndrome de dificultad respiratoria del adulto, falla renal aguda, disfunción hepática, choque hipovolémico $\mathrm{y}$, rara vez, compromiso cardíaco (50).

La primera descripción de la enfermedad se remonta a 1899, la cual fue inicialmente Ilamada "fiebre manchada de Idaho" por Edward Maxey (55). Posteriormente, gracias a estudios realizados en el estado de Montana (zona geográfica al noroeste de Estados Unidos donde se presentó inicialmente la enfermedad) por el patólogo estadounidense Howard Taylor Ricketts, en 1906, se determinó que la fiebre manchada de las Montañas Rocosas, era causada por microorganismos circulantes en garrapatas de la especie Dermacentor andersoni, en mamíferos silvestres y que, a su vez, eran transmitidas al hombre mediante la picadura de estos artrópodos (56). Desde esa época hasta nuestros días, siendo una rickettsiosis restringida al hemisferio occidental, esta enfermedad se ha descrito en varios países del continente americano desde Canadá hasta Argentina $(4,5)$.

En Estados Unidos, los principales vectores de $R$. rickettsii son $D$. variabilis en la región centro-este y la Costa Atlántica y $D$. andersoni en la región oeste (50). Los casos suelen ser más frecuentes en primavera y verano, cuando la actividad de estos vectores suele incrementarse (46). Según los datos de los Centers for Disease Control and Prevention (CDC) de Atlanta, la incidencia de fiebre manchada de las Montañas Rocosas se incrementó de menos de dos casos por millón de habitantes en el año 2000 , a ocho casos por millón de habitantes en el 2008, con una disminución en la tasa de letalidad, la cual pasó de $1,4 \%$ entre 1997 y 2002 a 0,5\% en el año 2008 (57); probablemente, esto se explica por un aumento en la sospecha clínica y el inicio de tratamiento adecuado y oportuno. En el año 2005, en el estado de Arizona, se reportó la especie $R$. sanguineus como vector de $R$. rickettsii (58), situación que ha explicado el aumento de casos en esta región de los Estados Unidos, especialmente en la población de indígenas americanos que habitan la zona suroeste (59).

En estudios recientes se demuestran bajas tasas 0 ausencia de infección por parte de $R$. rickettsii en $D$. variabilis en la región este, donde esta garrapata cohabita con otras especies, como Amblyomma 
americanum y $A$. maculatum, implicadas también como reservorios de $R$. rickettsii, al igual que de otras especies de Rickettsia menos patógenas, como $R$. parkeri y $R$. amblyommii (60). Por lo anterior, se han propuesto nuevas teorías sobre la eco-epidemiología de la fiebre manchada de las Montañas Rocosas en Estados Unidos, en las que se resalta el papel de nuevos vectores (61) y el concepto de reacción cruzada entre diferentes especies del grupo de las fiebres manchadas, lo cual explica la pequeña proporción de casos confirmados ante un gran número de sospechados (62).

Respecto a Suramérica, en Brasil, la fiebre manchada de las Montañas Rocosas se conoce como fiebre maculosa brasilera. Es la rickettsiosis de mayor importancia en este país, es de notificación obligatoria y está bajo vigilancia epidemiológica estricta desde el año 2001 (63). Fue descrita por primera vez en la ciudad de São Paulo, en 1929, como tifus exantemático de São Paulo, y posteriormente, en Minas Gerais y Rio de Janeiro (64). La mayoría de casos se concentran en estas regiones y algunos se han descrito en el estado de Bahía y el Distrito Federal (63). Las tasas de letalidad son considerablemente más altas que las reportadas en Estados Unidos, con un porcentaje aproximado de 20 a $30 \%$, explicado por dificultades en el diagnóstico y déficit en el tratamiento temprano (64), con presentaciones más graves de la enfermedad (65) e, incluso, cepas de $R$. rickettsii más virulentas respecto a las de otras regiones del continente (66).

Según datos del Ministerio de Salud de Brasil, en el período de 1997-2010, se notificaron 868 casos confirmados de fiebre maculosa brasilera con 227 muertes relacionadas en todo el territorio (63), donde la mayor incidencia se presentó en la región sudeste entre junio y octubre, lo que coincide con el período de mayor actividad de las formas inmaduras de $A$. cajennense, vector reconocido de $R$. rickettsii $(64,67)$. En el ecosistema de esta garrapata, los chigüiros o capibaras (Hydrochoerus hydrochaeris) juegan el papel de huéspedes principales para este artrópodo y amplificadores de la enfermedad, y su presencia es un factor de riesgo para el desarrollo de brotes de fiebre maculosa brasilera (68).

Otras especies de garrapatas, como $A$. aureolatum y $R$. sanguineus, también se han implicado como vectores de $R$. rickettsii en el estado de São Paulo, especialmente en el área metropolitana, donde los caninos domésticos hacen parte del ecosistema de ambas especies $(69,70)$. A su vez, en estudios recientes en la misma área, se demostraron altas tasas de seroprevalencia en estos animales (71), situación que llama la atención por su cercanía al hombre como animales de compañía y posibles amplificadores competitivos de la enfermedad, como se ha demostrado en otras especies de Rickettsia $(72,73)$.

En otros países de Centroamérica y Suramérica, durante el siglo XX, la fiebre manchada de las Montañas Rocosas ya era reconocida (74-78). En la última década, al igual que en Estados Unidos y Brasil, esta enfermedad ha presentado un patrón reemergente en México, Costa Rica, Panamá, Colombia y Argentina (5).

En México, el vector principal de $R$. rickettsii es $R$. sanguineus, caracterizado desde los años 40 $(79,80)$, seguido de $A$. cajennense (45). En algunos estudios publicados en 2010 se implica a $A$. imitator como un nuevo vector potencial (81). Es así como las regiones endémicas se restringen a los estados del norte, centro y suroeste de México $(82,83)$. En Costa Rica se describieron casos humanos desde 1977 hasta 2003, en los cuales se aisló $R$. rickettsii y se hizo detección molecular de esta especie en garrapatas Haemaphysalis leporispalustris (84). El último caso reportado en la literatura científica (2012) se presentó en la zona urbana de la ciudad de San José, donde murió una niña de ocho años de edad con presencia de escara de inoculación como hallazgo clínico interesante (85), al ser un signo excepcional dentro las manifestaciones de la fiebre manchada de las Montañas Rocosas (86).

En Panamá, después de un silencio epidemiológico de la enfermedad y de la descripción de $A$. cajennense como vector principal en los años $50(76,87)$, solo hasta 2004 y 2007 se confirmaron nuevos casos de mortalidad en pacientes pediátricos y una mujer embarazada $(88,89)$. Situaciones similares ocurren en Colombia y en Argentina $(90,91)$.

La "fiebre de Tobia" fue el nombre que le dio el doctor Luis Patiño a un brote febril de alta mortalidad indicativo de fiebre manchada de las Montañas Rocosas ocurrido en el "Valle de Tobia" (departamento de Cundinamarca, Colombia), en 1935 (77). Después de 70 años, en la misma región, se aisló $R$. rickettsii en estudios post mórtem de un paciente con síndrome febril agudo (90). Posteriormente, durante tres años consecutivos (2006 a 2008) se registraron nuevos casos en el noroccidente colombiano (municipios de Necoclí, Los Córdobas y Turbo), con tasas de letalidad entre 26 y $54 \%$ (92-94). En un estudio recientemente publicado, en el cual se 
describió la ecoepidemiología de la rickettsiosis en la zona del Urabá antioqueño, por medio de inmunofluorescencia indirecta (IFI), se demostraron títulos significativamente altos de lgG contra $R$. rickettsii, en muestras pareadas correspondientes a dos pacientes con síndrome febril agudo (1:4.096 y $1: 131.072,1: 8.192$ y 1:131.072, fase aguda y fase de convalecencia, respectivamente para cada individuo), que sugieren a $R$. rickettsii como agente etiológico; sin embargo, no se logró aislar esta especie de Rickettsia en ectoparásitos ni en roedores capturados en la zona de estudio (95).

En Argentina, después de las primeras descripciones de la enfermedad en 1999 (78), solo se ha reportado un brote con cuatro casos de mortalidad por fiebre manchada de las Montañas Rocosas en la provincia de Jujuy, entre 2003 y 2004 (91). Todos los casos refirieron picaduras por garrapatas antes del inicio del cuadro clínico febril, desarrollaron exantema petequial, hipotensión grave, convulsiones y finalmente la muerte. Se logró confirmar la infección por $R$. rickettsii en uno de los pacientes y en garrapatas $A$. cajennense recolectadas cerca de la zona del brote.

\section{Infección por Rickettsia parkeri}

La primera descripción de infección probable por $R$. parkerila hizoSpenceren 1926, al documentarel caso de un hombre de 35 años procedente de la costa de Virginia (Estados Unidos) con un cuadro clínico febril de evolución benigna asociado a cefalea, mialgias, exantema máculo-papular y escaras de inoculación (96). Estos hallazgos clínicos sugirieron la presencia de una enfermedad similar a la fiebre manchada de las Montañas Rocosas. Once años más tarde, el entomólogo y rickettsiólogo Ralph Robinson Parker, logró aislar la rickettsia que llevaría su apellido, en garrapatas $A$. maculatum (garrapata de la costa del golfo) recolectadas en ganado en Texas (97). Parker logró demostrar mediante sus investigaciones, el curso benigno de la enfermedad en animales de experimentación después de la inoculación con $R$. parkeri, en comparación con una enfermedad más grave tras la inoculación de $R$. rickettsii (97), y la producción de anticuerpos heterólogos en estos animales (98). Este hecho hizo clasificar de manera inicial a esta nueva especie dentro del grupo de las fiebres manchadas.

En 2004, se confirmó por primera vez la infección humana por $R$. parkeri en un hombre de 40 años procedente del mismo estado (Virginia) y con manifestaciones clínicas similares a las del paciente descrito en 1926. Presentó reacción cruzada por medio de IFI para anticuerpos de tipo IgG (título hasta $1: 1.024)$ contra $R$. rickettsii y $R$. parkeri. Sin embargo, esta última especie se logró aislar a partir de una de las escaras de inoculación. El paciente no requirió hospitalización y respondió rápidamente al tratamiento con doxiciclina (99). A partir de estos hallazgos, se inició la discusión en cuanto a la posibilidad de que otros casos sospechosos mas no confirmados de fiebre manchada de las Montañas Rocosas en Estados Unidos, con resultados menos graves y asociados a escara de inoculación, podrían explicarse por infecciones subdiagnosticadas de $R$. parkeri $(100,101)$.

Actualmente, en Estados Unidos, A. maculatum es el principal vector reconocido para $R$. parkeri, con tasas de infección entre 11 y 43 \% (102-104). Su distribución se restringe a los estados que se encuentran en el borde del golfo de México, la región sur y la central (Alabama, Arkansas, Carolina del Norte, Carolina del Sur, Florida, Georgia, Kansas, Kentucky, Mississippi, Oklahoma, Tennessee, Texas y Virginia) (21,102-107). Recientemente, se logró aislar ADN de $R$. parkeri en muestras de sangre de caninos domésticos en el sur del estado de Louisiana, región donde no existían reportes previos de este microorganismo (108).

Típicamente, la enfermedad causada por $R$. parkerise caracteriza por presentar un periodo de incubación de aproximadamente una semana, después del cual se inicia un cuadro clínico febril agudo (temperatura media de $39,2{ }^{\circ} \mathrm{C}$ ) asociado a astenia, mialgias, artralgias, cefalea y exantema generalizado máculopapular o vesículo-papular de predomino en tronco y extremidades, incluyendo palmas y plantas. De forma importante, se presenta escara de inoculación única o múltiple en más del $90 \%$ de los casos, la cual se puede acompañar de linfadenopatía en la zona contigua. La evolución suele ser benigna con bajas tasas de hospitalización o complicaciones (108). Hasta el año 2009, se habían reportado en Estados Unidos aproximadamente 19 casos probables o confirmados $(109,110)$.

En Uruguay, desde 1990 hasta el 2003, la enfermedad se confundió inicialmente con infección por $R$. conorii en casos clínicos febriles con presencia de escara de inoculación después de la picadura de garrapatas $A$. triste y pruebas serológicas positivas para $R$. conorii $(111,112)$. Ante estos resultados, en el 2004 se llevó a cabo un estudio en el que se confirmó la infección por $R$. parkeri en diferentes especímenes de $A$. triste recolectadas en el periodo entre 1999 y 2004, en 
diferentes regiones de Uruguay; esta especie de rickettsia se propuso como responsable de los casos sugestivos de rickettsiosis en este país, con una importante reacción cruzada con $R$. conorii en pruebas serológicas (113). En los años siguientes (2005-2007) se confirmaron tres casos de infección por $R$. parkeri por medio de la prueba serológica de absorción cruzada, previa prueba de reacción cruzada con antígenos de $R$. rickettsii. Todos los casos presentaron enfermedad febril, asociada a escara de inoculación, adenopatía regional y evolución favorable (114). En estudios recientes en la región sur de Uruguay, se demostraron tasas de infección por $R$. parkeri en $A$. triste, entre 11,8 y $37,5 \%$ (115).

En Brasil, en el año 2007, R. parkeri se aisló por primera vez en garrapatas $A$. triste recolectadas en el estado de São Paulo, con una tasa de infección aproximada del $10 \%$ (116). Tres años más tarde, en el mismo estado, se reportó el primer caso sugestivo de infección por $R$. parkeri en un hombre con enfermedad febril aguda, exantema macular y escara de inoculación en la región lumbar, en el cual se logró aislar ADN de rickettsias estrechamente relacionado con $R$. parkeri y $R$. africae, proponiéndose el nuevo aislamiento como cepa "Atlantic rainforest" de la especie $R$. parkeri. El estudio serológico por medio de IFI reveló reacción cruzada contra diferentes especies del grupo de las fiebres manchadas (25). Cabe aclarar que la región del bosque húmedo Atlántico en el territorio brasilero se extiende desde el estado de Rio Grande do Norte hasta el estado de Rio Grande do Sul.

En el año 2011, en el estado de Bahia, se reportó otro caso con características clínicas sugestivas de infección por $R$. parkeri (fiebre, mialgias, exantema papular en cara, tronco y extremidades superiores, escara de inoculación en muñeca y linfadenopatía axilar ipsilateral). La IFI demostró reacción cruzada entre $R$. parkeri y $R$. rickettsii; sin embargo, el ADN amplificado de la escara de inoculación se relacionó genéticamente con la cepa Atlantic rainforest, $R$. africae, $R$. parkeri y $R$. sibirica; por lo cual se le asignó el nombre de $R$. parkeri cepa Bahia (117). De otro lado, teniendo en cuenta estudios previos en que se demostraban características clínicas diferentes respecto a la fiebre maculosa brasilera (presencia de linfadenopatía, menos tasas de gravedad y ausencia de letalidad), se llevó a cabo un estudio en el estado de Santa Catarina (118) en el cual se demostró la presencia de $R$. parkeri cepa Atlantic rainforest en garrapatas $A$. aureolatum, $A$. ovale y $R$. sanguineus (119), las dos primeras encontradas frecuentemente parasitando seres humanos en Brasil (47). Lo anterior ha planteado la posibilidad de que garrapatas como $A$. aureolatum - A. ovale sean los vectores de $R$. parkeri cepa Atlantic rainforest en la región del bosque húmedo atlántico en los estados de Santa Catarina y São Paulo (120-122), lo cual explica en el primero parte del comportamiento clínico de las rickettsiosis confundidas con fiebre maculosa brasilera.

En estudios recientes en garrapatas recolectadas de aves de la región sur de Brasil, se demostró el aislamiento de nuevas cepas de R. parkeri (cepa NOD y cepa apPR), con capacidad patógena aún desconocida $(26,71,123)$.

En Argentina, el primer caso publicado como infección probable por $R$. parkeri se presentó en el año 2007 (124), en un hombre procedente de la localidad de Ingeniero Otamendi en la región del delta paranaense, quien presentó un cuadro clínico febril agudo asociado a escalofríos, sudoración nocturna, mialgias, cefalea, astenia, tos no productiva, exantema máculo-papular que respetaba palmas y plantas, y escara de inoculación en la región preauricular izquierda (con adenopatía regional) donde previamente había sido picado por una garrapata no identificada. Su evolución clínica fue favorable después del tratamiento ambulatorio con doxiciclina. La prueba de IFI fue positiva contra antígenos de $R$. rickettsii, lo cual se interpretó como una reacción cruzada dadas las manifestaciones clínicas de la enfermedad y el área de procedencia, donde $A$. triste se ha encontrado parasitando humanos y por su papel vectorial en Uruguay $(114,125)$. Años más tarde (2008 y 2011), se confirmó la presencia de $R$. parkeri tanto en garrapatas $A$. triste recolectadas en el delta del Paraná (126) como en material genético extraído de escaras de inoculación de pacientes procedentes de esta misma región y áreas rurales de la provincia de Buenos Aires y provincia del Chaco (127). En este último estudio se determinó que las manifestaciones clínicas presentadas por los pacientes en Argentina eran muy similares a las de los casos confirmados en Estados Unidos.

Recientemente, en el departamento de Cochabamba (Bolivia), se logró detectar $R$. parkeri en garrapatas A. tigrinum (tasa de infección de 54,8 \%) recolectadas de caninos domésticos, al igual que en una muestra de sangre tomada de estos animales (128). Sin embargo, a la fecha no existen reportes de casos clínicos indicativos de infección por $R$. parkeri en Bolivia. 


\section{Infección por Rickettsia massiliae}

Rickettsia massiliae se aisló por primera vez cerca a Marsella (Francia) en 1992, en garrapatas $R$. sanguineus $(129,130)$. Después de esto, se describió en países europeos y africanos, como Grecia (131), Portugal (132,133), España (134,135), Suiza (136), República Centroafricana y Malí (137), infectando diferentes especies del género Rhipicephalus, como $R$. sanguineus, $R$. turanicus, $R$. muhsamae, $R$. lunulatus y $R$. sulcatus.

En 1985, se reportó un caso de rickettsiosis inicialmente confundido con fiebre manchada del Mediterráneo, en un paciente de 45 años hospitalizado en Palermo (Italia) por presentar enfermedad febril aguda asociada a exantema máculo-papular que comprometía palmas y plantas, escara de inoculación en el tobillo derecho y ligera hepatomegalia. Fue tratado con tetraciclinas, tuvo una adecuada evolución clínica y presentó seroconversión por medio de IFI para $R$. conorii. Veinte años más tarde, se logró extraer y amplificar ADN de las muestras de este paciente, encontrándose material genético indicativo de $R$. massiliae (138). Un segundo caso se confirmó en el sur de Francia, en un paciente que desarrolló fiebre, cefalea, exantema máculo-papular, escara de inoculación en la axila izquierda y coriorretinitis bilateral (139).

En las Américas, esta especie se aisló inicialmente en garrapatas $R$. sanguineus del estado de Arizona (Estados Unidos) y, en la ciudad de Buenos Aires (Argentina) en el año 2004, sin presencia de casos clínicos relacionados $(7,9)$. Sin embargo, un año más tarde se presentó el primero y único caso de infección humana por $R$. massiliae reportado hasta la fecha en el hemisferio occidental (8). Se trataba de una mujer de 56 años procedente de Argentina con un cuadro clínico febril agudo, escalofríos, malestar general, y exantema purpúrico que comprometía tronco, extremidades, palmas y plantas. La paciente reportó presencia de garrapatas en su perro antes de su enfermedad, por lo cual se inició tratamiento con doxiciclina ante la sospecha de rickettsiosis. En el examen físico se observó una escara de inoculación en el muslo derecho, de la cual se tomó biopsia y se logró amplificar ADN indicativo de $R$. massiliae.

Recientemente, se reportó por primera vez la presencia de $R$. massiliae en garrapatas $R$. sanguineus en el estado de California (Estados Unidos), recolectadas en dos perros con enfermedad sugestiva de fiebre manchada de las
Montañas Rocosas. A pesar de que estos animales presentaron seroconversión por IFI para $R$. rickettsii, se logró determinar en uno de ellos infección por $R$. massiliae mediante la prueba de absorción cruzada y Western Blot (140).

\section{Infección por Rickettsia africae (fiebre africana transmitida por garrapatas)}

La primera descripción de esta enfermedad se hizo en Mozambique y Suráfrica, en 1911, donde se le dio el nombre de "fiebre transmitida por garrapatas" (141). Fue confundida con la fiebre manchada del Mediterráneo hasta mediados de 1930, cuando el patólogo Pijper, mientras trabajaba en la ciudad de Pretoria (Suráfrica), propuso que esta era una nueva rickettsiosis transmitida por garrapatas, de predominio rural, de características clínicas menos graves y relacionada con el contacto de las personas con garrapatas del ganado (142). A pesar de que el patólogo logró aislar el microorganismo y diferenciarlo de $R$. conorii, sus resultados no fueron reproducibles. Fue así como nuevamente los casos se siguieron diagnosticando de forma errónea como infección por R. conorii hasta los años 90 (45). En el periodo comprendido entre 1991 y 1996, Kelly, et al., lograron aislar el nuevo microorganismo en garrapatas $A$. hebraeum, $A$. variegatum y en muestras de pacientes de Zimbabue, y propusieron el nombre que aún se conserva para esta especie, $R$. africae, perteneciente al grupo de las fiebres manchadas (143-146).

La distribución actual de $R$. africae está determinada por la presencia de garrapatas vectores como $A$. variegatum, en las regiones este, oeste y central de África, al igual que en las islas del Caribe, y $A$. hebraeum, en la región sur de África (45). Rickettsia africae también se ha aislado en $A$. lepidum y $A$. variegatum en Sudán (noreste africano) (147), en Hyalomma dromedarii en Argelia (noroeste africano) (41) y Egipto (noreste africano) (148), en A. loculosum en Nueva Caledonia (Oceanía) (149), en Rhipicephalus (Boophilus) decoloratus en la República de Botsuana (Suráfrica) (150) y en $H$. aegyptium en Estambul (Turquía) (151).

La enfermedad se caracteriza clínicamente por un periodo de incubación entre 5 y 10 días. Suele presentarse fiebre de inicio abrupto, náuseas, cefalea, mialgias en región cervical y escara de inoculación única o múltiple (en más del $50 \%$ de los casos), de predominio en las extremidades inferiores, asociada a linfadenopatía regional. El exantema se presenta en la mitad de los casos y es vesicular o maculopapular (45). 
Rickettsia africae ingresó a las Américas durante el siglo XIX, en barcos procedentes de Senegal rumbo a la isla de Guadalupe (islas del Caribe), los cuales traían ganado parasitado con $A$. variegatum (152). El primer caso se describió en 1998, en una mujer francesa que adquirió la enfermedad después de la picadura por una garrapata en la isla de Guadalupe, y presentó fiebre, astenia y lesión nodular eritematosa. Fue tratada con doxiciclina, evolucionó adecuadamente y se determinó $R$. africae como agente etiológico por medio de la prueba de inmunoabsorción cruzada (14). Un año más tarde, en la misma isla, se confirmó la infección por esta especie en garrapatas $A$. variegatum y se demostraron altas seroprevalencias en humanos (49\%), bovinos (80,8 \%) y caprinos $(86,6 \%)(15)$.

A partir del año 2002, se han realizados varios estudios que demuestran que las islas del Caribe son un área endémica para $R$. africae, con las siguientes tasas de infección en $A$. variegatum: $84 \%$ en la isla de Antigua (2002) (152), $41 \%$ en las islas de San Cristóbal y Nieves (2003) (153), y $56 \%$ en la isla de La Martinica (2003) (17). El último estudio, de 2007 a 2009 (16), también reveló datos similares en otras islas: $50 \%$ en las Islas Vírgenes, $30 \%$ en la Isla Dominica, $40 \%$ en la isla de Monserrat y $7 \%$ en la isla de Santa Lucía. En este estudio también se demostraron altas tasas de seroprevalencia para rickettsias del grupo de las fiebres manchadas en bovinos, caprinos y ovinos.

Llama la atención que la mayoría de los casos clínicos reportados en pacientes que adquirieron la infección en estas islas, eran turistas y no habitantes de esta región $(14,154)$.

Hasta la fecha, $R$. africae no ha sido reportada en otras regiones de las Américas diferentes a las islas del Caribe.

\section{Infección por Rickettsia amblyommii}

Esta especie fue descrita por primera vez en garrapatas $A$. americanum del estado de Tennessee, en 1974, como parte del grupo de las fiebres manchadas y sin capacidad patógena conocida (155). En estudios posteriores se demostró que más del $40 \%$ de estas garrapatas se encontraban infectadas con $R$. amblyommii en las regiones sur y centro-oeste de Estados Unidos (18,156).

Solo en 1993 se planteó la posibilidad de que esta especie hubiese sido la causa de un brote febril en personal militar que se encontraba en los estados de Arkansas y Virginia. Por medio de Western Blot se logró determinar que algunos de estos pacientes presentaron reacción con proteínas antigénicas de $R$. amblyommii (157). Doce años más tarde, en otro estudio en el estado de Carolina del Norte, se determinó la seroconversión para $R$. amblyommii en pacientes con diagnóstico presuntivo de fiebre manchada de las Montañas Rocosas con prueba de IFI negativa para $R$. rickettsii. A su vez, en el mismo estudio, se encontraron garrapatas $A$. americanum infectadas con $R$. amblyommii (158).

Dados estos antecedentes, en la actualidad se plantea la posibilidad de que esta especie de rickettsia pueda causar cuadros clínicos febriles de evolución benigna, falsamente diagnosticados como fiebre manchada de las Montañas Rocosas u otras rickettsiosis, teniendo en cuenta la situación de reacción cruzada que se presenta por ser de un mismo grupo, en este caso, el grupo de las fiebres manchadas (5). Por su parte, esta misma situación también podría explicar las altas tasas de seroprevalencia para $R$. rickettsii en regiones donde no se presenta el número de casos esperados (43).

Cabe destacar que a la fecha, aparte de Estados Unidos, $R$. amblyommii se ha aislado en $A$. neumanni en Argentina (159), A. cajennense, $A$. coelebs, $A$. longirostre y $A$. geayi en Brasil (160163), A. cajennense en Costa Rica (164), A. coelebs en la Guyana Francesa (165) y $A$. cajennense, $R$. sanguineus y Dermacentor nitens en Panamá $(166,167)$.

\section{Retos en el diagnóstico}

Debido a que la gran mayoría de las manifestaciones clínicas de las rickettsiosis son inespecíficas (fiebre, cefalea, malestar general, mialgias y artralgias, entre otras) y, por lo mismo, compartidas con otras enfermedades infecciosas, especialmente virales y bacterianas, se han enmarcado dentro de los diagnósticos diferenciales del síndrome febril agudo, tanto en áreas urbanas como tropicales (45). De igual manera, entre las mismas rickettsiosis se presentan signos similares, como el exantema - la escara de inoculación que, a pesar de sugerir infección por esta familia de microorganismos (Rickettsiaceae), no logran determinar de manera concreta un agente etiológico preciso. También, los hallazgos hematológicos y bioquímicos comunes a las rickettsiosis (trombocitopenia, anormalidad en el número de leucocitos, elevación moderada de enzimas hepáticas, etc.) son solo una prueba indirecta de la fisiopatología de la enfermedad que, en algunos casos, puede tener un comportamiento variable según el tiempo de evolución y su 
gravedad en el paciente. Cabe resaltar que, al ser enfermedades transmitidas por artrópodos vectores, y en algunos casos de distribución geográfica definida, una adecuada anamnesis sobre los antecedentes epidemiológicos puede orientar al médico a un diagnóstico presuntivo (45).

Dentro de este contexto, en la actualidad se cuenta con métodos diagnósticos directos e indirectos útiles para identificar el agente infeccioso, tanto en la fase aguda de la enfermedad (pruebas moleculares, inmunohistoquímica y cultivo celular) como de forma retrospectiva (métodos serológicos), estos últimos sólo confirmatorios o útiles para estudios epidemiológicos (cuadro 2).

La prueba serológica por medio de IFI es el método de referencia (cuadro 2). Sin embargo, aunque este método es de fácil acceso y manejo, es de utilidad diagnóstica retrospectiva $\mathrm{y}$, debido a las características antigénicas compartidas, presenta reacciones cruzadas entre las diferentes especies del género Rickettsia, sobre todo cuando pertenecen a un mismo grupo (grupo de las fiebres manchadas, grupo del tifus, etc.) (168). Esta es la prueba más utilizada en las Américas para estudios de seroprevalencia y como método diagnóstico frente a infecciones por rickettsias.

Otro método en el cual se utilizan muestras de suero, es el Western Blot asociado a inmunoabsorción cruzada. Tiene la gran ventaja de identificar la especie de Rickettsia involucrada en determinada infección, descartando reacciones cruzadas con otras especies. Esta prueba se basa en la absorción de anticuerpos homólogos y heterólogos presentes en el suero del paciente que, posteriormente, son verificados por medio del Western Blot al unirse o no hacerlo a proteínas antigénicas de las diferentes especies de Rickettsia. Si se presenta la absorción de ambos anticuerpos, la especie de Rickettsia utilizada en la mezcla con el suero, se identifica como el agente etiológico; mientras que, si únicamente se remueven los anticuerpos heterólogos, la especie en la mezcla se identifica como el agente causal de la reacción cruzada.

Cabe aclarar que este es un método costoso y que requiere de tiempo considerable de dedicación, ya que se deben mantener viables

Cuadro 2. Aproximaciones diagnósticas en rickettsiosis.

\begin{tabular}{|c|c|c|c|}
\hline Método & Muestra & Prueba & Notas \\
\hline Serológico & Muestras de suero & $\begin{array}{l}\text { Inmunofluorescencia } \\
\text { indirecta }\end{array}$ & $\begin{array}{l}\text { *Es el método de referencia } \\
\text { * IgM o lgG. Seroconversión en } \\
\text { muestras pareadas con elevación } \geq 4 \\
\text { títulos o } \geq 2 \text { veces la dilución }\end{array}$ \\
\hline $\begin{array}{l}\text { Estudio con } \\
\text { Western Blot }\end{array}$ & Muestras de suero & $\begin{array}{l}\text { Western Blot } \\
\text { asociado a } \\
\text { inmunoabsorción } \\
\text { cruzada }\end{array}$ & $\begin{array}{l}\text { * Distingue entre diferentes especies } \\
\text { en algunos casos, también entre } \\
\text { otras bacterias intracelulares. } \\
\text { * Únicamente disponibles en centro } \\
\text { diagnóstico de referencia }\end{array}$ \\
\hline Pruebas moleculares & $\begin{array}{l}\text { Muestra de sangre } \\
\text { con anticoagulante EDTA, } \\
\text { biopsias de piel, líquido } \\
\text { cefalorraquídeo, muestras } \\
\text { de tejidos conservados en } \\
\text { parafina, artrópodos capturados }\end{array}$ & $\begin{array}{l}\text { PCR convencional o } \\
\text { PCR en tiempo real }\end{array}$ & $\begin{array}{l}\text { *Prueba de tamización con qPCR } \\
\text { para definir el grupo al que pertenece } \\
\text { la especie de Rickettsia } \\
\text { * Prueba confirmatoria con PCR } \\
\text { convencional: amplificación de genes } \\
\text { específicos ( gltA, rOmpA, rOmpB, } \\
16 S \text { rRNA, sca4) }\end{array}$ \\
\hline $\begin{array}{l}\text { Histología e } \\
\text { inmunohistoquímica }\end{array}$ & $\begin{array}{l}\text { Especímenes de tejidos fijados } \\
\text { con formalina o conservados en } \\
\text { parafina }\end{array}$ & $\begin{array}{l}\text { Tinciones de Giemsa o } \\
\text { Gimenez }\end{array}$ & $\begin{array}{l}\text { * Los métodos de inmunohistoquímica } \\
\text { proveen mejor visualización de } \\
\text { rickettsias del grupo de las fiebres } \\
\text { manchadas. }\end{array}$ \\
\hline Cultivo & $\begin{array}{l}\text { Muestra de sangre con } \\
\text { anticoagulante EDTA, biopsias } \\
\text { de piel o artrópodos capturados }\end{array}$ & $\begin{array}{l}\text { Cultivo celular (células Vero, } \\
\text { L929, HEL, XTC-2 o MRC5), } \\
\text { detección de antigenos en } \\
\text { cultivo (Shell vial) }\end{array}$ & $\begin{array}{l}\text { * Se requiere laboratorios de } \\
\text { referencia con nivel de seguridad P3. } \\
\text { * Se requiere personal capacitado } \\
\text { para el mantenimiento de cultivos } \\
\text { celulares vivos. }\end{array}$ \\
\hline
\end{tabular}

Reproducido con el permiso de Elsevier (número de licencia 3043681089803) de: Kernif T, Socolovschi C, Bitam I, Raoult D, Parola P. Vector-borne rickettsioses in North Africa. Infect Dis Clin N Am. 2012;26:455-78. http://dx.doi.org/10.1016/j.idc.2012.03.007 
numerosas especies de este género para llevar a cabo las pruebas (168). Este método se utiliza en laboratorios de referencia de Europa, para establecer un diagnóstico retrospectivo del agente etiológico involucrado en cuadros clínicos sugestivos de rickettsiosis. Por el contrario, en las Américas, el Western Blot asociado a inmunoabsorción cruzada no se utiliza de rutina y son pocos los casos publicados en el hemisferio occidental donde determinan la especie de Rickettsia involucrada en infecciones humanas utilizando este método (14).

Los otros métodos, como la inmunohistoquímica, el cultivo celular y la amplificación por medio de qPCR y PCR convencional de genes conservados del género Rickettsia, se vienen utilizando con mayor frecuencia en el mundo, de forma única y en combinación, siendo posible la determinación de las especies patógenas de Rickettsia, de una forma rápida, eficaz y directa,. Estos métodos son los únicos que pueden proveer un diagnóstico acertado durante la fase aguda de la enfermedad. Sin embargo, las muestras de mayor accesibilidad en los pacientes, como las de sangre, no suelen contener el suficiente número de microorganismos para su adecuada amplificación y caracterización. La mayor utilidad de estos métodos está en casos con lesiones dermatológicas que se prestan para practicar biopsia y que contienen considerable número de microorganismos viables, como la escara de inoculación (168).

\section{Conclusiones}

Es claro que a lo largo del tiempo, hasta nuestros días, las rickettsiosis transmitidas por garrapatas en las Américas han adquirido un papel importante entre las enfermedades emergentes y reemergentes causantes de cuadros febriles agudos, brotes o, inclusive, epidemias. Cada vez son más las publicaciones de nuevos aislamientos de especies de la familia Rickettsiaceae en, artrópodos vectores, animales y seres humanos, lo que se relaciona con nuevas descripciones de síndromes clínicos y permite aportes a la ecoepidemiología de estas enfermedades.

Hasta finales del siglo XX, las rickettsiosis de mayor impacto y reconocimiento en el hemisferio occidental eran la fiebre manchada de las Montañas Rocosas, el tifus murino y el tifus epidémico. En el presente siglo, dados los múltiples estudios de investigación y las nuevas herramientas de diagnóstico y caracterización de microorganismos, se ha demostrado el papel de especies como R. parkeri, probablemente sub- diagnosticada, como responsables de nuevas enfermedades, que se superponen en antiguas zonas endémicas para fiebre manchada de las Montañas Rocosas. Además, las rickettsiosis asociadas a escara de inoculación (considerada hasta hace algunos años como un signo clínico infrecuente en las Américas), se han caracterizado recientemente, abriendo las posibilidades diagnósticas, de forma similar a lo que sucede con la epidemiología de las rickettsiosis transmitidas por garrapatas en Europa, África y Asia.

El continente americano también ha sido responsable del aislamiento y los estudios de seroprevalencia sobre nuevas especies de importancia, como $R$. amblyommii, cuyo papel como patógeno, a pesar de discutirse, puede causar altas tasas de seroprevalencia para rickettsias del grupo de las fiebres manchadas 0 , incluso, causar infecciones subclínicas o asintomáticas.

Con lo anterior, son evidentes la complejidad y el reto diagnóstico que presentan las rickettsiosis transmitidas por garrapatas en las Américas, lo que amerita la búsqueda de una mejor caracterización de las especies circulantes. Probablemente, los métodos diagnósticos, como la IFI, fueron de mayor utilidad en años pasados, cuando demostraron la circulación del género Rickettsia en diferentes regiones y permitieron diagnosticar casos probables, dada la reacción cruzada propia de este método, sin que se pudiera establecer claramente el agente etiológico en cuestión. Sin embargo, la identificación específica de las diferentes especies de Rickettsia descritas en las Américas, se ha logrado mediante técnicas de biología molecular, definiéndose zonas endémicas para dichas rickettsiosis.

Finalmente, consideramos la incursión e investigación en nuevos métodos diagnósticos sensibles y específicos de aplicación en la fase aguda de la enfermedad, cuando el diagnóstico apropiado permitiría un tratamiento antibiótico oportuno. Esto es particularmente importante dado el diagnóstico diferencial con otras enfermedades causantes de síndrome febril agudo.

\section{Conflicto de intereses}

Los autores declaran que no tienen conflictos de intereses.

\section{Financiación}

Los autores declaran no haber recibido ningún tipo de financiación para la realización del presente manuscrito. 


\section{Referencias}

1. Renvoisé A, Raoult D. An update on rickettsiosis. Med Mal Infect.2009;39:71-81.http://dx.doi.org/10.1016/j.medmal. 2008. 11.003

2. Mansueto P, Vitale G, Cascio A, Seidita A, Pepe I, Carroccio A, et al. New insight into immunity and immunopathology of rickettsial diseases. Clin Dev Immunol. 2012;2-26. http://dx.doi.org/10.1155/2012/967852

3. Merhej V, Raoult D. Rickettsial evolution in the light of comparative genomics. Biol Rev Camb Philos Soc. 2011; 86:379-405.http://dx.doi.org/10.1111/j.1469-185X.2010.00 151.x

4. Renvoisé A, Mediannikov O, Raoult D. Old and new tickborne rickettsioses. Int Health. 2009;1:17-25. http://dx.doi. org/10.1016/j.inhe.2009.03.003

5. Parola $\mathbf{P}$, Labruna $\mathbf{M}$, Raoult $\mathbf{D}$. Tick-borne rickettsioses in America: Unanswered questions and emerging diseases. Curr Infect Dis Rep. 2009;11:40-50. http://dx.doi. org/10.1007/s11908-009-0007-5

6. Labruna M, Máttar S, Nava S, Bermúdez S, Venzal J, Dolz G, et al. Rickettsiosis in Latin America, Caribbean, Spain and Portugal. Rev MVZ Córdoba. 2011;16:2435-57.

7. Cicuttin GL, Rodríguez M, Jado I, Anda P. Primera detección de Rickettsia massiliae en la Ciudad de Buenos Aires. Resultados preliminares. Rev Arg Zoonosis. 2004;1:8-10.

8. García JC, Portillo A, Núñez MJ, Santibáñez S, Castro B, Oteo JA. Case report: A patient from Argentina infected with Rickettsia massiliae. Am J Trop Hyg. 2010;82:691-2. http:// dx.doi.org/10.4269/ajtmh.2010.09-0662

9. Eremeeva ME, Bosserman EA, Demma LJ, Zambrano ML, Blau DM, Dasch GA. Isolation and identification of Rickettsia massiliae from Rhipicephalus sanguineus ticks collected in Arizona. Appl Environ Microbiol. 2006;72:556977. http://dx.doi.org/10.1128/AEM.00122-06

10. Tomassone L, Conte V, Parrilla G, De Meneghi D. Rickettsia infection in dogs and Rickettsia parkeri in Amblyomma tigrinum ticks, Cochabamba Department, Bolivia. Vector Borne Zoonotic Dis. 2010;10:953-8. http:// dx.doi.org/10.1089/vbz.2009.0126

11. Dergousoff SJ, Gajadhar AJ, Chilton NB. Prevalence of Rickettsia species in Canadian populations of Dermacentor andersoni and $D$. variabilis. Appl Environ Microbiol. 2009;75:1786-9. http://dx.doi.org/10.1128/AEM.02554-08

12. Carmichael JR, Fuerst PA. A rickettsial mixed infection in a Dermacentor variabilis tick from Ohio. Ann N Y Acad Sci. 2006;1078:334-7. http://dx.doi.org/10.1196/annals.1374.064

13. Labruna MB, Camargo LM, Camargo EP, Walker DH. Detection of spotted fever group Rickettsia in the tick Haemaphysalis juxtakochi in Rondonia, Brazil. Vet Parasitol. 2005;127:169-74. http://dx.doi.org/10.1016/j. vetpar.2004.09.024

14. Parola P, Jourdan J, Raoult D. Tick-borne infection caused by Rickettsia africae in the West Indies. N Engl $\mathrm{J}$ Med. 1998;338:1391.

15. Parola P, Vestris G, Martínez D, Brochier B, Roux V, Raoult D. Tick-borne rickettsiosis in Guadeloupe, the Frech West Indias: Isolation of Rickettsia africae from Amblyomma variegatum ticks and serosurvey in humans, cattle, and goats. Am J Trop Med Hyg. 1999;60:888-93.

16. Kelly P, Lucas H, Beati L, Yowell C, Mahan S, Dame J. Rickettsia africae in Amblyomma variegatum and domestic ruminants on eight Caribbean islands. J Parasitol. 2010;96:1086-8. http://dx.doi.org/10.1645/GE-2552.1

17. Parola P, Attali J, Raoult D. First detection of Rickettsia africae on Martinique, in the French West Indies. Ann Trop Med Parasitol. 2003:97;535-7.

18. Kelly DJ, Carmichael JR, Booton GC, Poetter KF, Fuerst PA. Novel spotted fever group rickettsiae (SFGR) infecting Amblyomma americanum ticks in Ohio, USA. Ann N Y Acad Sci. 2005;1063:352-5. http://dx.doi.org/10.1196/ annals. 1355.058

19. Pacheco RC, Moraes-Filho J, Nava S, Brandao PE, Richtizenhain LJ, Labruna M. Detection of a novel spotted fever Group rickettsia in Amblyomma parvum ticks (Acari: Ixodidae) from Argentina. Exp Appl Acarol. 2007;43:63-71. http://dx.doi.org/10.1007/s10493-007-9099-5

20. Blair PJ, Jiang J, Schoeler GB, Moron C, Anaya E, Cóspedes M, et al. Characterization of spotted fever group rickettsiae in flea and tick specimens from Northern Peru. J Clin Microbiol. 2004;42:4961-7. http://dx.doi.org/10.1128/ JCM.42.11.4961-4967.2004

21. Fornadel $\mathbf{C M}$, Zhang $X$, Smith JD, Paddock CD, Arias JR, Norris DE. High rates of Rickettsia parkeri infection in Gulf Coast ticks (Amblyomma maculatum) and identification of "Candidatus Rickettsia andeanae" from Fairfax County, Virginia. Vector Borne Zoonotic Dis. 2011;11:1535-9. http:// dx.doi.org/10.1089/vbz.2011.0654

22. Abarca K, López J, Acosta-Jamett G, Lepe P, Soares JF, Labruna MB. A third Amblyomma species and the first tickborne rickettsia in Chile. J Med Entomol. 2012;49:219-22

23. Pacheco RC, Moraes-Filho J, Marcili A, Richtizenhain LJ, Szabó MP, Catroxo MH, et al. Rickettsia monteiroi sp. nov. infecting the tick Amblyomma incisum in Brazil. Appl Environ Microbiol. 2011;77:5207-11. http://dx.doi. org/10.1128/AEM.05166-11

24. Almeida AP, Cunha LM, Bello AC, da Cunha AP, Domingues LN, Leite RC, et al. A novel Rickettsia infecting Amblyomma dubitatum ticks in Brazil. Ticks Tick Borne Dis. 2011;2:209-12. http://dx.doi.org/10.1016/j.ttbdis. 2011.08.003

25. Spolidorio MG, Labruna MB, Mantovani E, Brandao PE, Richtizenhain LJ, Yoshinari NH. Novel spotted fever group rickettsiosis, Brazil. Emerg Infect Dis. 2010;16:521-3. http://dx.doi.org/10.3201/eid1603.091338

26. Ogrzewalska M, Martins T, Miroslav C, Literak I, Labruna MB. A Rickettsia parkeri-like agent infecting Amblyomma calcaratum nymphs from birds in Mato Grosso do Sul, Brazil. Ticks Tick Borne Dis. 2012;7:1-10. http://dx.doi. org/10.1016/j.ttbdis.2012.07.001

27. Silva N, Eremeeva ME, Rozental T, Ribeiro GS, Paddock CD, Ramos EA, et al. Eschar-associated spotted fever rickettsiosis, Bahia, Brazil. Emerg Infect Dis. 2011;17:275-8. http://dx.doi.org/10.3201/eid1702.100859

28. Miranda J, Portillo A, Oteo JA, Máttar S. Rickettsia sp. strain colombianensi (Rickettsiales: Rickettsiaceae): A new proposed Rickettsia detected in Amblyomma dissimile 
(Acari: Ixodidae) from iguanas and free-living larvae ticks from vegetation. J Med Entomol. 2012;49:960-5

29. Shapiro MR, Fritz CL, Tait K, Paddock CD, Nicholson WL, Abramowicz KF, et al. Rickettsia 364D: A newly recognized cause of eschar-associated illness in California. Clin Infect Dis. 2010;50:541-8. http://dx.doi.org/10.1086/649926

30. Phan JN, Lu CR, Bender WG, Smoak RM 3rd, Zhong J. Molecular detection and identification of Rickettsia species in Ixodes pacificus in California. Vector Borne Zoonotic Dis. 2011;11:957-61. http://dx.doi.org/10.1089/vbz.2010.0077

31. Ogrzewalska M, Literak I, Cárdenas-Callirgos JM, Capek M, Labruna MB. Rickettsia bellii in ticks Amblyomma varium Koch, 1844, from birds in Peru. Ticks Tick Borne Dis. 2012;3:254-6. http://dx.doi.org/10.1016/j.ttbdis.2012.05.003

32. Carmichael JR, Fuerst PA. A rickettsial mixed infection in a Dermacentor variabilis tick from Ohio. Ann N Y Acad Sci.2006;1078:334-7.http://dx.doi.org/10.1196/annals. 1374.064

33. McKiel JA, Bell EJ, Lackman DB. Rickettsia canada: A new member of the typhus group of rickettsiae isolated from Haemaphysalis leporispalustris ticks in Canada. Can J Microbiol. 1967;13:503-10. http://dx.doi.org/10.1139/m67-065

34. Philip RN, Casper EA, Anacker RL, Peacock MG, Hayes SF, Lane RS. Identification of an isolate of Rickettsia canada from California. Am J Trop Med Hyg. 1982;31:1216-21.

35. Olano JP. Rickettsial infections. Ann N Y Acad Sci. 2005; 1063:187-96.http://dx.doi.org/10.1196/annals. 1355.031

36. Yu XJ, Walker D. The order rickettsiales. Prokaryotes. 2006;5:493-528.http://dx.doi.org/10.1007/0-387-30745-1_20

37. Dantas-Torres F, Chomel BB, Otranto D. Ticks and tickborne diseases: A one health perspective. Trends Parasitol. 2012;16:1-10. http://dx.doi.org/10.1016/j.pt.2012.07.003

38. Uchiyama T. Tropism and pathogenicity of rickettsiae. Front Microbiol. 2012;3:1-11. http://dx.doi.org/10.3389/ fmicb.2012.00230

39. Valbuena G, Walker DH. Infection of the endothelium by members of the order Rickettsiales. Thromb Haemost. 2009;102:1071-9. http://dx.doi.org/10.1160/TH09-03-0186

40. Elston DM. Rickettsial skin disease: Uncommon presentations. Clin Dermatol. 2005;23:541-4. http://dx.doi. org/10.1016/j.clindermatol.2005.01.016

41. Kernif T, Socolovschi C, Bitam I, Raoult D, Parola P. Vector-borne rickettsioses in North Africa. Infect Dis Clin N Am. 2012;26:455-78. http://dx.doi.org/10.1016/j. idc.2012.03.007

42. Labruna MB. Ecology of Rickettsia in South America. Ann N Y Acad Sci. 2009;1166:156-66. http://dx.doi.org/10.1111/ j.1749-6632.2009.04516.x

43. Walker DH. Rickettsial diseases of the Americas. Biomédica. 2011;31:11.

44. Guglielmone AA, Robbins RG, Apanaskevich DA, Petney TN, Estrada-Pena A, Horak IG, et al. The Argasidae, Ixodidae and Nuttalliellidae (Acari: Ixodida) of the world: A list of valid species names. Zootaxa. 2010;2528:1-28.

45. Parola P, Paddock CD, Raoult D. Tick-borne rickettsioses around the world: Emerging diseases challenging old concepts. Clin Microbiol Rev. 2005;18:719-56. http://dx.doi. org/10.1128/CMR.18.4.719-756.2005

46. Chapman AS, Bakken JS, Folk SM, Paddock CD, Bloch KC, Krusell A, et al. Diagnosis and management of tickborne rickettsial diseases: Rocky Mountain spotted fever, ehrlichioses, and anaplasmosis -United States: A practical guide for physicians and other health-care and public health professionals. MMWR Recomm Rep. 2006;55:1-27.

47. Guglielmone AA, Beati L, Barros-Battesti DM, Labruna MB, Nava S, Venzal JM, et al. Ticks (Ixodidae) on humans in South America. Exp Appl Acarol. 2006;40:83-100. http:// dx.doi.org/10.1007/s10493-006-9027-0

48. Walker DH, Paddock CD, Dumler JS. Emerging and re-emerging tick-transmitted rickettsial and ehrlichial infections. Med Clin North Am. 2008;92:1345-61. http://dx. doi.org/10.1016/j.mcna.2008.06.002

49. Chen LF, Sexton DJ. What's new in Rocky Mountain spotted fever? Infect Dis Clin North Am. 2008;22:415-32. http://dx.doi.org/10.1016/j.idc.2008.03.008

50. Lin L, Decker CF. Rocky mountain spotted fever. Dis Mon. 2012;58:361-9. http://dx.doi.org/10.1016/j.disamonth. 2012.03.008

51. Cunha BA. Clinical features of Rocky Mountain spotted fever. Lancet Infect Dis. 2008;8:143-4. http://dx.doi.org/10.1016/ S1473-3099(08)70022-7

52. Dantas-Torres F. Rocky mountain spotted fever. Lancet Infect Dis. 2007;7:724-32. http://dx.doi.org/10.1016/S14733099(07)70261-X

53. Myers SA, Sexton DJ. Dermatologic manifestations of arthropod-borne diseases. Infect Dis Clin North Am. 1994; 8: 689-712

54. Sexton DJ, Corey GR. Rocky Mountain "spotless" and "almost spotless" fever: A wolf in sheep's clothing. Clin Infect Dis. 1992;439-48. http://dx.doi.org/10.1093/clind/15.3.439

55. Maxey EE. Some observations on the so-called spotted fever of Idaho. Med Sentinel. 1899;7:433-8.

56. Gross D. Schafer G. $100^{\text {th }}$ anniversary of the death of Ricketts: Howard Taylor Ricketts (1871-1910). The namesake of the Rickettsiaceae family. Microbes Infect. 2010;13:10-3. http:// dx.doi.org/10.1016/j.micinf.2010.09.008

57. CDC. Summary of notifiable diseases -United States 2009. MMWR. Morb Mortal Wkly Rep. 2011;58:1-104.

58. Demma LJ, Traeger MS, Nicholson WL, Paddock CD, Blau DM, Eremeeva ME, et al. Rocky Mountain spotted fever from an unexpected tick vector in Arizona. N Engl J Med. 2005;353:587-94. http://dx.doi.org/10.1056/NEJMoa 050043

59. Folkema AM, Holman RC, McQuiston JH, Cheek JE. Trends in clinical diagnoses of Rocky Mountain spotted fever among American Indians, 2001-2008. Am J Trop Med Hyg. 2012;86:152-8. http://dx.doi.org/10.4269/ajtmh.2012.110269

60. StromdahI EY, Jiang J, Vince M, Richards AL. Infrequency of Rickettsia rickettsii in Dermacentor variabilis removed from humans, with comments on the role of other human-biting ticks associated with spotted fever group Rickettsiae in the United States. Vector Borne Zoonotic Dis. 2011;11:969-7. http://dx.doi.org/10.1089/vbz.2010.0099 
61. Breitschwerdt EB, Hegarty BC, Maggi RG, Lantos PM, Aslett DM, Bradley JM. Rickettsia rickettsii transmission by a lone star tick, North Carolina. Emerg Infect Dis. 2011;17:873-5. http://dx.doi.org/10.3201/eid1705.101530

62. Openshaw JJ, Swerdlow DL, Krebs JW, Holman RC, Mandel E, Harvey A, et al. Rocky Mountain spotted fever in the United States, 2000-2007: Interpreting contemporary increases in incidence. Am J Trop Med Hyg. 2010;83:17482. http://dx.doi.org/10.4269/ajtmh.2010.09-0752

63. Pinter A, França AC, de Souza CE, Sabbo C, Mendes do Nascimento EM, Pereira dos Santos FC, et al. Febre maculosa brasileira. São Paulo: Centro de Produção e Divulgação Científica; 2011. Volume 8. p. 1-34

64. Del Fiol FS, Junqueira FM, Rocha MCP, Toledo MI, Barberato Filho S. A febre maculosa no Brasil. Rev Panam Salud Pública. 2010;27:461-6

65. Angerami RN, Resende MR, Feltrin AF, Katz G, Nascimento EM, Stucchi RS, et al. Brazilian spotted fever: A case series from an endemic area in southeastern Brazil clinical aspects. Ann N Y Acad Sci. 2006;1078:252-4. http:// dx.doi.org/10.1196/annals.1374.044

66. Eremeeva ME, Klemt RM, Santucci-Domotor LA, Silverman DJ, Dasch GA. Genetic analysis of isolates of Rickettsia rickettsii that differ in virulence. Ann N Y Acad Sci. 2003;990:717-22.

67. Guedes E, Leite RC, Prata MC, Pacheco RC, Walker DH, Labruna MB. Detection of Rickettsia rickettsii in the tick Amblyomma cajennense in a new Brazilian spotted fever-endemic area in the state of Minas Gerais. Mem Inst Oswaldo Cruz. 2005;100:841-5. http://dx.doi.org/10.1590/ S0074-02762005000800004

68. Angerami RN, Resende MR, Feltrin AF, Katz G, Nascimento EM, Stucchi RS, et al. Brazilian spotted fever: A case series from an endemic area in southeastern Brazil, epidemiological aspects. Ann NYAcad Sci. 2006;1078:170-2. http://dx.doi.org/10.1196/annals.1374.044

69. Labruna MB, Ogrzewalska M, Soares JF, Martins TF, Soares HS, Moraes-Filho J, et al. Experimental infection of Amblyomma aureolatum ticks with Rickettsia rickettsii. Emerg Infect Dis. 2011;17:829-34. http://dx.doi.org/10.3201/ eid1705.101524

70. Moraes-Filho J, Pinter A, Pacheco RC, Gutmann TB, Barbosa SO, Gonzáles MA, et al. New epidemiological data on Brazilian spotted fever in an endemic area of the state of São Paulo, Brazil. Vector Borne Zoonotic Dis. 2009;9:73-8. http://dx.doi.org/10.1089/vbz.2007.0227

71. Ogrzewalska M, Saraiva DG, Moraes-Filho J, Martins TF Costa FB, Pinter A, et al. Epidemiology of Brazilian spotted fever in the Atlantic Forest, state of São Paulo, Brazil. Parasitology. 2012;139:1283-300. http://dx.doi.org/10.1017/ S0031182012000546

72. Levin ML, Killmaster LF, Zemtsova GE. Domestic dogs (Canis familiaris) as reservoir hosts for Rickettsia conorii. Vector Borne Zoonotic Dis. 2012;12:28-33. http://dx.doi. org/10.1089/vbz.2011.0684

73. Hii SF, Kopp SR, Abdad MY, Thompson MF, O'Leary CA, Rees RL, et al. Molecular evidence supports the role of dogs as potential reservoirs for Rickettsia felis. Vector Borne Zoonotic Dis. 2011;11:1007-12. http://dx.doi. org/10.1089/vbz.2010.0270
74. Bustamante ME, Varela G, Mariotte CO. Estudios de fiebre manchada en México. Fiebre manchada en la Laguna. Rev Inst Salub Enferm Trop. 1946;7:39-49.

75. Fuentes LG. Primer caso de fiebre manchada de las Montañas Rocosas en Costa Rica, América Central. Rev Latinoam Microbiol. 1979;21:167-72.

76. de Rodaniche EC, Rodaniche A. Spotted fever in Panama; isolation of the etiologic agent from fatal case. Am J Trop Med Hyg. 1950;30:511-7.

77. Patiño L, Afanador A, Paul JH. A spotted fever in Tobia, Colombia. Am J Trop Med. 1937;17:639-53.

78. Ripoll CM, Remondegui CE, Ordóñez G, Arazamendi R, Fusaro $\mathrm{H}$, Hyman MJ, et al. Evidence of rickettsial spotted fever and ehrlichial infections in subtropical territory of Jujuy, Argentina. Am J Trop Med Hyg. 1999;61:350-4.

79. Bustamante ME, Varela G. Estudios de fiebre manchada en México. Papel del Rhipicephalus sanguineus en la transmisión de la fiebre manchada en la República Mexicana. Rev Inst Salub Enferm Trop. 1947;8:139-41.

80. Mariotte CO, Bustamante ME, Varela G. Hallazgos del Rhipicephalus sanguineus Latreille infectado naturalmente con fiebre manchada de las Montañas Rocosas, en Sonora (México) 1944. Rev Inst Salub Enferm Trop. 1944;5:297300.

81. Oliveira KA, Pinter A, Medina-Sánchez A, Boppana VD, Wikel SK, Saito TB, et al. Amblyomma imitator ticks as vectors of Rickettsia rickettsii, Mexico. Emerg Infect Dis.2010;16:1282-4.http://dx.doi.org/10.3201/eid1608. 100231

82. Martínez-Medina MA, Padilla-Zamudio G, Solís-Gallardo LP, Guevara-Tovar M. Rocky mountain spotted fever: Report of two cases. Gac Med Mex. 2005;141:309-12.

83. Zavala-Castro JE, Zavala-Velázquez JE, Walker DH, Ruiz-Arcila EE, Laviada-Molina H, Olano JP, et al. Fatal human infection with Rickettsia rickettsii, Yucatán, México. Emerg Infect Dis. 2006;12:672-4.

84. Hun L, Cortés X, Taylor L. Molecular characterization of Rickettsia rickettsii isolated from human clinical samples and from the rabbit tick Haemaphysalis leporispalustris collected at different geographic zones in Costa Rica. Am J Trop Med Hyg. 2008;79:899-902.

85. Argüello AP, Hun L, Rivera P, Taylor L. A fatal urban case of rocky mountain spotted fever presenting an eschar in San Jose, Costa Rica. Am J Trop Med Hyg. 2012;87:345-8. http://dx.doi.org/10.4269/ajtmh.2012.12-0153

86. Walker DH, Gay RM, Valdés-Dapena M. The occurrence of eschars in Rocky Mountain spotted fever. J Am Acad Dermatol. 1981;4:571-6. http://dx.doi.org/10.1016/S01909622(81)70059-8

87. de Rodaniche E. Natural infection of the tick, Amblyomma cajennenses, with Rickettsia rickettsii in Panama. Am J Trop Med Hyg. 1953;2:696-9.

88. Estripeaut D, Aramburú MG, Sáez-Llorens X, Thompson HA, Dasch GA, Paddock CD, et al. Rocky Mountain spotted fever, Panama. Emerg Infect Dis. 2007;13:1763-5. http://dx.doi.org/10.3201/eid1311.070931

89. Tribaldos $\mathbf{M}$, Zaldivar $\mathbf{Y}$, Bermúdez $\mathbf{S}$, Samudio $\mathbf{F}$, Mendoza Y, Martinez AA, et al. Rocky Mountain spotted 
fever in Panama: A cluster description. J Infect Dev Ctries. 2011;5:737-41

90. Hidalgo M, Orejuela L, Fuya P, Carrillo P, Hernández J, Parra E, et al. Rocky Mountain spotted fever, Colombia. Emerg Infect Dis. 2007;13:1058-60. http://dx.doi.org/10.3201 / eid1307.060537

91. Paddock CD, Fernández S, Echenique GA, Summer JW, Reeves WK, Zaki SR, et al. Rocky Mountain spotted fever in Argentina. Am J Trop Med Hyg. 2008;78:687-92.

92. Acosta J, Urquijo L, Díaz A, Sepúlveda M, Mantille G, Heredia D, et al. Brote de rickettsiosis en Necoclí, Antioquia, febrero-marzo de 2006. Inf Quinc Epidemiol Nac. 2006;11:177-92.

93. Hidalgo M, Miranda J, Heredia D, Zambrano P, Vesga JF, Lizarazo D, et al. Outbreak of Rocky Mountain spotted fever in Córdoba, Colombia. Mem Inst Oswaldo Cruz. 2011;106:117-8.http://dx.doi.org/10.1590/S0074-027620 11000100019

94. Pacheco-García OE, Giraldo MR, Hidalgo M, Galeano A, Echeverri I, Echavarría-Rodríguez L, et al. Estudio de brote febril hemorrágico en el corregimiento de Alto de Mulatos - Distrito Especial Portuario de Turbo, Antioquia, enero de 2008. Inf Quinc Epidemiol Nac. 2008;13:14560.

95. Quintero JC, Londoño AF, Díaz FJ, Agudelo-Flórez P, Arboleda M, Rodas JD. Ecoepidemiología de la infección por rickettsias en roedores, ectoparásitos y humanos en el noroeste de Antioquia, Colombia. Biomédica. 2013;33(Supl.1):38-51.

96. Spencer RR. A case of typhus-like fever following tick bite. Public Health Rep. 1926;41:2523-4.

97. Parker RR, Kohls GM, Cox GW, Davis GE. Observations on an infectious agent from Amblyomma maculatum. Public Health Rep. 1939;54:1482-4.

98. Lackman DB, Parker RR, Gerloff RK. Serological characteristics of a pathogenic Rickettsia ocurring in Amblyomma maculatum. Public Health Rep. 1949;64:1342-9.

99. Paddock CD, Summer JW, Comer JA, Zaki SR, Goldsmith CS, Goddard J, et al. Rickettsia parkeri: A newly recognized cause of spotted fever rickettsiosis in the United States. Clin Infect Dis. 2004;38:805-11. http://dx.doi. org/10.1086/381894

100. Paddock CD. Rickettsia parkeri as a paradigm for multiple causes of tick-borne spotted fever in the western hemisphere. Ann N Y Acad Sci. 2005;1063:315-26. http:// dx.doi.org/10.1196/annals.1355.051

101. Raoult D, Paddock CD. Rickettsia parkeri infection and other spotted fevers in the United States. N Engl J Med. 2005;353:626-7.

102. Summer JW, Durden LA, Goddard J, Stromdahl EY, Clark KL, Reeves WK, et al. Gulf Coast ticks (Amblyomma maculatum) and Rickettsia parkeri, United States. Emerg Infect Dis. 2007;13:751-3.

103. Wright CL, Nadolny RM, Jiang J, Richards AL, Sonenshine DE, Gaff HD, et al. Rickettsia parkeri in gulf coast ticks, southeastern Virginia, USA. Emerg Infect Dis. 2011;17:896-8. http://dx.doi.org/10.3201/ eid1705.101836
104. Varela-Stockes AS, Paddock CD, Engber B, Toliver M. Rickettsia parkeri in Amblyomma maculatum ticks, North Carolina, USA, 2009-2010. Emerg Infect Dis. 2011;17:2350-3.http://dx.doi.org/10.3201/eid1712. 110789

105. Goddard J, Norment BR. Notes on the geographical distribution of the Gulf Coast tick, Amblyomma maculatum (Koch) [Acari:Ixodidae]. Entomol News. 1983;94:103-4.

106. Jiang J, Stromdahl EY, Richards AL. Detection of Rickettsia parkeri and Candidatus Rickettsia andeanae in Amblyomma maculatum Gulf Coast ticks collected from humans in the United States. Vector Borne Zoonotic Dis. 2012;12:175-82. http://dx.doi.org/10.1089/vbz.2011.0614

107. Ferrari FAG, Goddard J, Paddock C, Varela-Stokes AS. Rickettsia parkeri and Candidatus Rickettsia andeanae in Gulf Coast ticks, Mississippi, USA. Emerg Infect Dis. 2012;18:1705-6. http://dx.doi.org/10.3201/ eid1810.120250

108. Grasperge BJ, Wolfson W, Macaluso KR. Rickettsia parkeri infection in domestic dogs, Southern Louisiana, USA, 2011. Emerg Infect Dis. 2012;18:995-7. http://dx.doi. org/10.3201/eid1806.120165

109. Paddock CD, Finley RW, Wright CS, Robinson HN, Schrodt BJ, Lane CC, et al. Rickettsia parkeri rickettsiosis and its clinical distinction from Rocky Mountain spotted fever. Clin Infect Dis. 2008;47:1188-96. http://dx.doi.org/10. 1086/592254

110. Cragun WC, Bartlett BL, Ellis MW, Hoover AZ, Tyring SK, Mendoza $\mathbf{N}$, et al. The expanding spectrum of eschar-associated rickettsioses in the United States. Arch Dermatol. 2010;146:641-8. http://dx.doi.org/10.1001/ archdermatol.2010.48

111. Conti-Diaz IA, Rubio I, Somma-Moreira RE, PerezBormida G. Lymphatic cutaneous rickettsiosis caused by Rickettsia conorii in Uruguay. Rev Inst Med Trop Sao Paulo. 1990;32:313-8.

112. Diaz IA. Rickettsiosis caused by Rickettsia conorii in Uruguay. Ann N Y Acad Sci. 2003;990:264-6.

113. Venzal JM, Portillo A, Estrada-Peña A, Castro O, Cabrera PA, Oteo JA. Rickettsia parkeri in Amblyomma triste from Uruguay. Emerg Infect Dis. 2004;10:1493-5. http://dx.doi.org/10.3201/eid1008.030999

114. Conti-Diaz IA, Moraes-Filho J, Pacheco RC, Labruna MB. Serological evidence of Rickettsia parkeri as the etiological agent of rickettsiosis in Uruguay. Rev Inst Med Trop Sao Paulo. 2009;51:337-9. http://dx.doi.org/10.1590/ S0036-46652009000600005

115. Venzal JM, Estrada-Peña A, Portillo A, Manglod AJ, Castro O, De Souza CG, et al. Rickettsia parkeri: A rickettsial pathogen transmitted by ticks in endemic areas for spotted fever rickettsiosis in southern Uruguay. Rev Inst Med Trop Sao Paulo. 2012;54:131-4. http://dx.doi. org/10.1590/S0036-46652012000300003

116. Silveira I, Pacheco RC, Szabó MP, Ramos HG, Labruna MB. Rickettsia parkeri in Brazil. Emerg Infect Dis. 2007;13:1111-3. http://dx.doi.org/10.3201/eid1307.061397

117. Silva N, Ereemeva ME, Rozental T, Ribeiro GS, Paddock CD, Ramos EA, et al. Eschar-associated spotted fever rickettsiosis, Bahia, Brazil. Emerg Infect Dis. 2011;17:275-8. http://dx.doi.org/10.3201/eid1702.100859 
118. Angerami RN, da Silva AM, Nascimento EM, Colombo S, Wada MY, dos Santos FC, et al. Brazilian spotted fever: Two faces of a same disease? A comparative study of clinical aspects between an old and a new endemic area in Brazil. Clin Microbiol Infect. 2009;15:207-8. http://dx.doi. org/10.1111/j.1469-0691.2008.02160.x

119. Madeiros AP, de Souza AP, de Moura AB, Lavina MS, Bellato V, Sartor AA, et al. Spotted fever group Rickettsia infecting ticks (Acari: Ixodidae) in the state of Santa Catarina, Brazil. Mem Inst Oswaldo Cruz. 2011;106:92630. http://dx.doi.org/10.1590/S0074-02762011000800005

120. Sabatini GS, Pinter A, Nieri-Bastos FA, Marcili A, Labruna MB. Survey of ticks (Acari: Ixodidae) and their Rickettsia in an Atlantic rain forest reserve in the State of São Paulo, Brazil. J Med Entomol. 2010;47:913-6.

121. Szabó MPJ, Nieri-Bastos FA, Spolidorio MG, Martins TF, Labruna MB. Isolation, characterization and ecological aspects of the Atlantic rainforest Rickettsia, the causative agent of a novel spotted fever rickettsiosis in Brazil. Biomédica. 2011;31:87-102.

122. Barbieri ARM, Szabó MPJ, Nieri-Bastos FA, Souza Junior JC, Labruna MB. Deteccion of a spotted fever group rickettsia in Amblyomma ovale (Acari: Ixodidae) from Blumenau, souther Brazil. Biomédica. 2011;31:103-13.

123. Pacheco RC, Arzua M, Nieri-Bastos FA, Moraes-Filho J, Marcili A, Richtzenhain LJ, et al. Rickettsial infection in ticks (Acari: Ixodidae) collected on birds in southern Brazil. J Med Entomol. 2012;49:710-6. http://dx.doi.org/10.1603/ ME11217

124. Seijo A, Picollo M, Nicholson W, Paddock C. Rickettsial spotted fever in the Paraná Delta. An emerging disease. Medicina (B. Aires). 2007;67:723-6.

125. Guglielmone AA, Nava S. Las garrapatas argentinas del género Amblyomma (Acari: Ixodidae): Distribución y huéspedes. RIA. 2006;35:133-53.

126. Nava S, Elshenawy Y, Eremeeva ME, Summer JW, Mastropaolo M, Paddock CD. Rickettsia parkeri in Argentina. Emerg Infect Dis. 2008;14:1894-7. http://dx.doi. org/10.3201/eid1412.080860

127. Romer Y, Seijo AC, Crudo F, Nicholson WL, VarelaStokes A, Lash RR, et al. Rickettsia parkeri rickettsiosis, Argentina. Emerg Infect Dis. 2011;17:1169-73. http://dx.doi. org/10.3201/eid1707.101857

128. Tomassone L, Conte V, Parrilla G, De Meneghi D. Rickettsia infection in dogs and Rickettsia parkeri in Amblyomma tigrinum ticks, Cochabamba Department, Bolivia. Vector Borne Zoonotic Dis. 2010;10:953-8. http:// dx.doi.org/10.1089/vbz.2009.0126

129. Beati L, Finidori JP, Gilot B, Raoult D. Comparison of serologic typing, sodium dodecyl sulfate-polyacrylamide gel electrophoresis protein analysis, and genetic restriction fragment length polymorphism analysis for identification of rickettsiae: Characterization of two new rickettsial strains. J Clin Microbiol. 1992;30:1922-30.

130. Beati L, Raoult D. Rickettsia massiliae sp. nov., a new spotted fever group Rickettsia. Int J Syst Bacteriol. 1993; 43:839-40.

131. Babalis T, Tselentis Y, Roux V, Psaroulaki A, Raoult D. Isolation and identification of a rickettsial strain related to
Rickettsia massiliae in Greek ticks. Am J Trop Med Hyg. 1994;50:365-72.

132. Bacellar F, Regnery RL, Núncio MS, Filipe AR. Genotypic evaluation of rickettsial isolates recovered from various species of ticks in Portugal. Epidemiol Infect. 1995; $114: 169-78$

133. Santos-Silva MM, Sousa R, Santos AS, Melo $P$, Encarnação V, Bacellar F. Ticks parasitizing wild birds in Portugal: Detection of Rickettsia aeschlimannii, R. helvetica and R. massiliae. Exp Appl Acarol. 2006;39:331-8.

134. Beati L, Roux V, Ortuño A, Castella J, Porta FS, Raoult D. Phenotypic and genotypic characterization of spotted fever group Rickettsiae isolated from Catalan Rhipicephalus sanguineus ticks. J Clin Microbiol. 1996;34:2688-94.

135. Fernández-Soto $\mathbf{P}$, Pérez-Sánchez R, Díaz-Martin V, Encinas-Grandes A, Álamo-Sanz R. Rickettsia massiliae in ticks removed from humans in Castilla y León, Spain. Eur J Clin Microbiol Infect Dis. 2006;25:811-3.

136. Bernasconi MW, Casati S, Péter O, Piffaretti JC. Rhipicephalus ticks infected with Rickettsia and Coxiella in Southern Switzerland (Canton Ticino). Infect Genet Evol. 2002;2:111-20.http://dx.doi.org/10.1016/S1567-1348 (02)00092-8

137. Dupont HT, Cornet JP, Raoult D. Identification of rickettsiae from ticks collected in the Central African Republic using the polymerase chain reaction. Am J Trop Med Hyg. 1994;50:373-80.

138. Vitale G, Mansuelo S, Rolain JM, Raoult D. Rickettsia massiliae human isolation. Emerg Infect Dis. 2006; 12: 174-5.

139. Parola P, Socolovschi C, Jeanjean L, Bitam I, Fournier PE, Sotto A, et al. Warmer weather linked to tick attack and emergence of severe rickettsioses. Plos Negl Trop Dis.2008;2:e338.http://dx.doi.org/10.1371/journal.pntd. 0000338

140. Beeler E, Abramowicz KF, Zambrano ML, Sturgeon MM, Khalaf N, Hu R, et al. A focus of dogs and Rickettsia massiliae-infected Rhipicephalus sanguineus in California. Am J Trop Med Hyg. 2011;84:244-9. http://dx.doi.org/ 10.4269/ ajtmh.2011.10-0355

141. McNaught JG. A tick-borne fever in the Union of South Africa. J R Army Med Corps. 1911;16:505.

142. Pijper A, Crocker GC. Rickettsioses of South Africa. S Afri Med J. 1938;12:613-60.

143. Kelly PJ, Manson P. Transmission of spotted fever group rickettsia by Amblyomma hebraeum (Acari: Ixodidae). J Med Entomol. 1991;28:596-600.

144. Kelly PJ, Matthewman L, Beati L, Raoult D, Manson $\mathbf{P}$, Dreary $\mathbf{M}$, et al. African tick-bite fever: A new spotted fever group rickettsiosis under an old name. Lancet. 1992;340:982-3.http://dx.doi.org/10.1016/0140-6736 (92)92878-J

145. Kelly PJ, Beati L, Matthewman L, Manson P, Dasch GA, Raoult D. A new pathogenic spotted fever group rickettsia from Africa. J Trop Med Hyg. 1994;97:129-37.

146. Kelly PJ, Beati L, Manson P, Matthewman L, Roux V, Raoult D. Rickettsia africae sp. nov., the etiological agent of African tick bite fever. Int J Syst Bacteriol. 1996;46:611-4. http://dx.doi.org/10.1099/00207713-46-2-611 
147. Morita C, El Hussein AR, Matsuda E, Abdel Gabbar KM, Muramatsu Y, Abdel Rahman MB, et al. Spotted fever group rickettsiae from ticks captured in Sudan. Jpn I Infect Dis. 2004;57:107-9.

148. Abdel-Shafy S, Allam NA, Mediannikov O, Parola P, Raoult D. Molecular detection of spotted fever group rickettsiae associated with ixodid ticks in Egypt. Vector Borne Zoonotic Dis. 2012;12:346-59. http://dx.doi.org/ 10.1089/vbz.2010.0241

149. Eldin C, Mediannikov O, Davoust B, Cabre O, Barré N, Raoult $\mathrm{D}$, et al. Emergence of Rickettsia africae, Oceania. Emerg Infect Dis. 2011;17:100-2. http://dx.doi.org/10.3201/ eid1701.101081

150. Portillo A, Pérez-Martínez L, Santibáñez S, Blanco JR, Ibarra V, Oteo JA. Detection of Rickettsia africae in Rhipicephalus (Boophilus) decoloratus ticks from the Republic of Botswana, South Africa. Am J Trop Med Hyg. 2007;77:376-7.

151. Gargili A, Palomar AM, Midilli K, Portillo A, Kar S, Oteo JA. Rickettsia species in ticks removed from humans in Istanbul, Turkey. Vector Borne Zoonotic Dis. 2012;12:93841. http://dx.doi.org/10.1089/vbz.2012.0996

152. Kelly PJ. Rickettsia africae in the West Indies. Emerg Infect Dis. 2006;12:24-6. http://dx.doi.org/10.3201/eid1202. 050903

153. Kelly PJ, Fournier PE, Parola P, Raoult D. A survey for spotted fever group rickettsiae and ehrlichiae in Amblyomma variegatum from St. Kitts and Nevis. Am J Trop Med Hyg. 2003;69:58-9.

154. Raoult D, Fournier PE, Fenollar F, Jensenius M, Prioe T, de Pina JJ, et al. Rickettsia africae, a tickborne pathogen in travelers to sub-Saharan Africa. $\mathrm{N}$ Engl J Med. 2001;17:1504-10. http://dx.doi.org/10.1056/ NEJM200105173442003

155. Burgdorfer W, Hayes SF, Thomas LA, Lancaster JL. A new spotted fever group rickettsia from the Lone Star Tick, Amblyomma americanum. New York: Academic Press; 1981. p. 595-602.

156. Goddard J, Norment BR. Spotted fever group rickettsiae in the lone star tick, Amblyomma americanum (Acari: Ixodidae). J Med Entomol. 1986;23:465-72.

157. Dasch GA, Kelly DJ, Richards AL, Sánchez JL, Rives CC. Western blotting analysis of sera from military personnel exhibiting serological reactivity to spotted fever group Rickettsiae. Am Soc Trop Med Hyg. 1993;49:220.

158. Apperson CS, Engber B, Nicholson WL, Mead DG, Engel J, Ybsley MJ, et al. Tick-borne diseases in North Carolina: Is "Rickettsia amblyommir" a possible cause of rickettsiosis reported as Rocky Mountain spotted fever? Vector Borne Zoonotic Dis. 2008;8:597-606. http://dx.doi. org/10.1089/vbz.2007.0271
159. Labruna MB, Pacheco RC, Nava S, Brandão PE, Richtzenhain LJ, Guglielmone AA. Infection by Rickettsia bellii and Candidatus "Rickettsia amblyommii" in Amblyomma neumanni ticks from Argentina. Microb Ecol. 2007;54:126-33.http://dx.doi.org/10.1007/s00248-0069180-3

160. Labruna MB, Whitworth T, Bouyer DH, McBride JW, Camargo LMA, Camargo EP, et al. Rickettsia bellii and Rickettsia amblyommii in Amblyomma ticks from the state of Rondônia, Western Amazon, Brazil. J Med Entomol. 2004;41:1073-81.http://dx.doi.org/10.1603/0022-2585-41.6. 1073

161. Ogrzewalska M, Pacheco RC, Uezu A, Ferreira F, Labruna MB. Ticks (Acari: Ixodidae) infesting wild birds in an Atlantic Forest area in the State of São Paulo, Brazil, with isolation of Rickettsia from the tick Amblyomma longirostre. J Med Entomol. 2008;45:770-4. http://dx.doi. org/10.1603/0022-2585(2008)45[770:TAIIWB]2.0.CO;2

162. Ogrzewalska M, Uezu A, Labruna MB. Ticks (Acari: Ixodidae) infesting wild birds in the eastern Amazon, Northern Brazil, with notes on rickettsial infection in ticks. Parasitol Res. 2010;106:809-16. http://dx.doi.org/10.1007/ s00436-010-1733-1

163. Ogrzewalska M, Uezu A, Labruna MB. Ticks (Acari: Ixodidae) infesting wild birds in the Atlantic Forest in northeastern Brazil, with notes on rickettsial infection in ticks.Parasitol Res. 2011;108:665-70.http://dx.doi.org/ 10.1007/s00436-010-2111-8

164. Hun L, Troyo A, Taylor L, Barbieri AM, Labruna MB. First report of the isolation and molecular characterization of Rickettsia amblyommii and Rickettsia felis in Central America. Vector Borne Zoonotic Dis. 2011;11:1395-7. http:// dx. doi.org/10.1089/vbz.2011.0641

165. Parola P, Matsumoto K, Socolovschi C, Parzy D, Raoult D. A tick-borne rickettsia of the spotted-fever group, similar to Rickettsia amblyommii, in French Guyana. Ann Trop Med Parasitol. 2007;101:185-8. http://dx.doi. org/10.1179/136485907154557

166. Bermúdez SE, Zaldívar Y, Spolidorio M, Moraes-Filho $\mathbf{J}$, Miranda R, Caballero C, et al. Rickettsial infection in domestic mammals and their ectoparasites in El Valle de Antón, Coclé, Panamá. Vet Parasitol. 2011;177:134-8. http://dx.doi.org/10.1016/j.vetpar.2010.11.020

167. Bermúdez SE, Eremeeva ME, Karpathy SE, Samudio FE, Zambrano ML, Zaldívar YL, et al. Detection and identification of Rickettsial agents in ticks from domestic mammals in Eastern Panama. J Med Entomol. 2009;46:85661. http://dx.doi.org/10.1603/033.046.0417

168. Raoult D, Parola P. Rickettsial diseases. New York: Informa Healthcare; 2007. p. 315-30. 